\title{
Infiltration of Plasma Cells in the Iris of Children With ANA-Positive Anterior Uveitis
}

\author{
Viera Kalinina Ayuso, ${ }^{1}$ Marijke R. van Dijk, ${ }^{2}$ and Joke H. de Boer ${ }^{1}$ \\ ${ }^{1}$ Department of Ophthalmology, University Medical Center Utrecht, Utrecht, The Netherlands \\ ${ }^{2}$ Department of Pathology, University Medical Center Utrecht, Utrecht, The Netherlands
}

Correspondence: Viera Kalinina Ayuso, Department of Ophthalmology, University Medical Center Utrecht, L. 02.417, Heidelberglaan 100,3584 CX Utrecht, The Netherlands;

v.kalininaayuso@umcutrecht.nl.

Submitted: May 26, 2015

Accepted: August 31, 2015

Citation: Kalinina Ayuso V, van Dijk MR, de Boer JH. Infiltration of plasma cells in the iris of children with ANApositive anterior uveitis. Invest $O p h$ thalmol Vis Sci. 2015;56:6770-6778 DOI:10.1167/iovs.15-17351
Purpose. We investigated inflammatory cell infiltrates in iris biopsies in uveitis associated with juvenile idiopathic arthritis (JIA) in comparison with other pediatric uveitis entities and noninflammatory pediatric controls.

Methods. Iridectomy specimens were obtained during elective trabeculectomy from 31 eyes of 25 patients: 12 eyes with JIA-associated uveitis, 13 eyes with other uveitis entities, and 6 eyes with open angle nonuveitic juvenile glaucoma. Histopathologic and immunohistochemical analyses were performed. A semiquantitative scoring system was used with a scale ranging from 0 to 4 depending on the number of stained cells.

Results. An inflammatory infiltrate was present in 8/12 (67\%) specimens with JIA-associated uveitis. The cellular infiltrate in JIA specimens was characterized by the presence of CD138+ plasma cells and CD68+ macrophages, while the presence of $\mathrm{CD} 20+, \mathrm{CD} 4+$, and CD8+ cells was variable. Presence of plasma cells in the inflammatory infiltrates in anterior uveitis correlated with antinuclear autoantibody (ANA) positivity regardless of the diagnosis of JIA. CD4 + and CD8 $+\mathrm{T}$ cells were not always detectable in the iris biopsies of all childhood uveitis patients, although a slight predominance of CD4+ cells was noted.

Conclusions. Children with ANA-positive anterior uveitis often show an infiltrate of plasma cells, regardless of the diagnosis of JIA. The iris of JIA-associated uveitis patients is additionally characterized by the presence of various numbers of macrophages.

Keywords: plasma cells, pediatric uveitis, JIA, ANA
$\mathrm{U}$ veitis in childhood is a potentially blinding condition with juvenile idiopathic arthritis (JIA) being the most common systemic association. ${ }^{1}$ Juvenile idiopathic arthritis-associated uveitis is characterized by its anterior localization, with the iris and ciliary body being the primary sites of inflammation. ${ }^{2-5}$ Despite intensive research, the pathogenesis of the simultaneous inflammation of the eye and joint in JIA remains unknown. Animal models have shown that uveitis is predominantly a T-cell-mediated disease. ${ }^{6}$ However, in humans, the histopathologic and immunohistochemical features of uveitis still are poorly characterized due to limited availability of tissue. Almost all available histopathologic reports of JIA-associated uveitis concern the end-stage of the disease. These case reports have implicated a role for B cells, as evidenced by the heavy infiltration of plasma cells and CD20+ cells in tissue specimens obtained from enucleated eyes and sector iridectomies of patients with JIA-associated uveitis. ${ }^{2-5}$

In the present study we present histopathologic and immunohistochemical findings in a relatively large number of iris specimens obtained during therapeutic glaucoma surgery of children with uveitis associated with JIA, other uveitis entities, and pediatric nonuveitis controls.

\section{Materials ANd Methods}

\section{Iris Tissue and Data Collection}

Iris tissue samples were obtained from 31 eyes of 25 patients between 2009 and 2012 during elective trabeculectomy with mitomycin and peripheral iridectomy at the Department of Ophthalmology, University Medical Center Utrecht, The Netherlands. Of these samples, 25 were collected from 25 eyes of 19 children with uveitis diagnosed before the age of 16 years and 6 specimens from 6 eyes of 5 children with open-angle nonuveitic glaucoma. A total of 12 eyes had JIA-associated uveitis (10 antinuclear autoantibody [ANA]-positive and 2 ANAnegative) and 13 eyes were from uveitis patients with an unknown etiology (anterior uveitis, $n=10$; intermediate uveitis, $n=2$; and panuveitis, $n=1$ ). These latter 13 patients were ANA-positive. Of the specimens, 24 were collected and examined prospectively, while 7 were taken from a storage archive and reexamined. A written informed consent was obtained from the parents and/or the patients before the iris tissue sampling. The study was performed in accordance with the Declaration of Helsinki for research involving human tissue and was approved by the Institutional Review Board. Diagnosis of uveitis was based on the criteria of the Standardization of Uveitis Nomenclature (SUN) Workgroup. Diagnosis of JIA was made by a pediatric rheumatologist according to the criteria from the International League against Rheumatism (ILAR). ${ }^{7,8}$ Trabeculectomy was performed under general anaesthesia by an experienced surgeon specialized in childhood uveitis and pediatric glaucoma (JHB). Trabeculectomy was performed if antiglaucomatous topical therapy had failed to control IOP, in case of an increase in pathologic optic disc cupping, or progression of visual field defects. It is generally approved to perform intraocular surgery when the eye is quiet for at least 3 

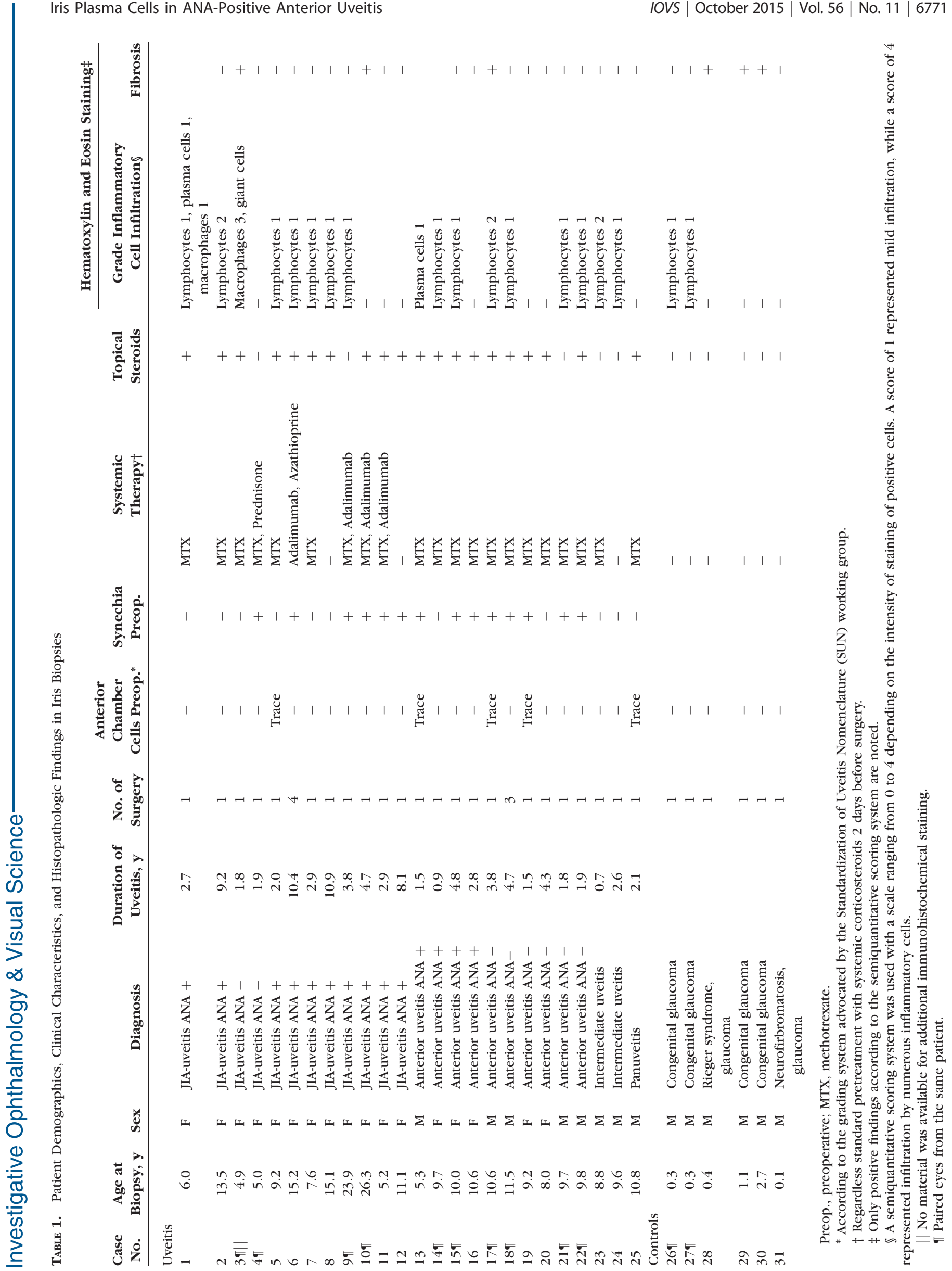


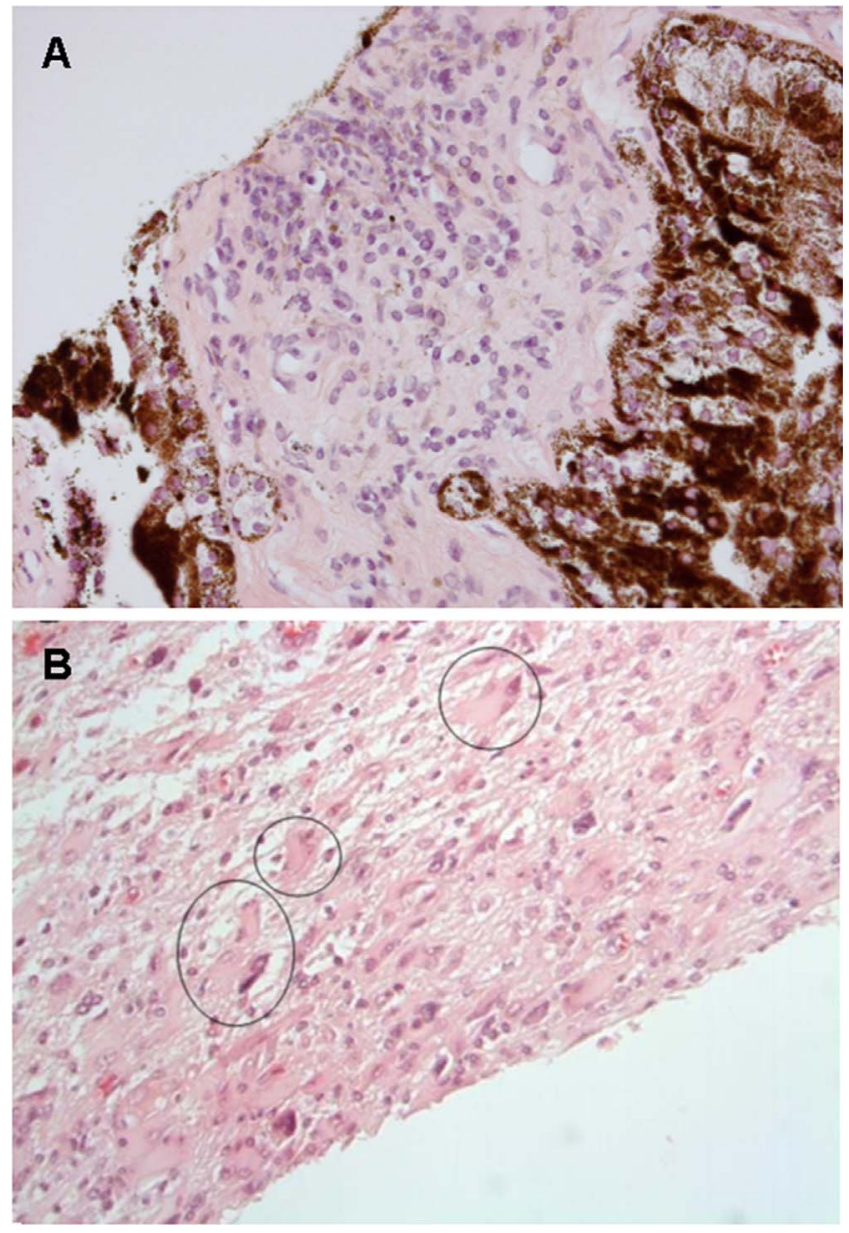

Figure 1. Histopathologic analysis of iridectomy specimens obtained during elective trabeculectomy in children with anterior uveitis associated with JIA. Magnification: $10 \times 20$. Hematoxylin and eosin staining (A) Case 2 (JIA ANA-positive). (B) Case 3 (JIA ANA-negative). (A) Moderate nongranulomatous inflammation. (B) Picture typical for nonnecrotizing granulomatous inflammation characterized by the presence of giant cells (marked with circles).

TABLE 2. Results of Immunohistochemical Staining of Iridectomy Specimens in Cases With Presence of Inflammatory Cells in HE Staining

\begin{tabular}{|c|c|c|c|c|c|c|c|c|c|c|}
\hline Case No. & Diagnosis & ANA & Age, $y$ & Age of Uveitis Onset, y & Duration of Uveitis, $y$ & CD20 & CD4 & CD8 & CD68 & CD138 \\
\hline 1 & Oligoarticular JIA-uveitis & + & 6.0 & 3.3 & 2.7 & 2 & 3 & 2 & 3 & 3 \\
\hline 2 & Oligoarticular JIA-uveitis & + & 13.5 & 4.3 & 9.2 & - & 2 & - & 1 & 2 \\
\hline $5^{*}$ & Oligoarticular JIA-uveitis & + & 9.2 & 7.2 & 2.0 & - & - & - & 1 & 3 \\
\hline 8 & Oligoarticular JIA-uveitis & + & 15.1 & 4.2 & 10.9 & - & 1 & 1 & 2 & 2 \\
\hline $13^{*}$ & Anterior uveitis & + & 5.3 & 1.5 & 3.8 & $2 \ddagger$ & 2 & - & NM & 2 \\
\hline 14 & Anterior uveitis & + & 9.7 & 8.8 & 0.9 & - & - & 2 & - & 1 \\
\hline $17^{*} \dagger$ & Anterior uveitis & - & 10.6 & 6.8 & 3.8 & - & 2 & 2 & - & NM \\
\hline $18 \dagger$ & Anterior uveitis & - & 11.5 & 6.8 & 4.7 & - & 2 & - & 2 & - \\
\hline 21 & Anterior uveitis & - & 9.7 & 7.9 & 1.8 & - & 2 & 2 & - & - \\
\hline 23 & Intermediate uveitis & - & 8.8 & 8.1 & 0.7 & 1 & 2 & - & 1 & NM \\
\hline 24 & Intermediate uveitis & _- & 9.6 & 7.0 & 2.6 & - & 1 & - & - & - \\
\hline 26 & Congenital glaucoma & NT & 0.3 & NA & NA & - & - & 2 & 2 & - \\
\hline
\end{tabular}

RF, rheumatoid factor; NA, not applicable; NM, no material available for analysis; NT, not tested.

* Eyes with a trace of anterior chamber cells shortly previous to trabeculectomy due to an urgent indication.

† Paired eyes.

‡ Focal arrangement. 


\section{ANA+ JIA CD4+ T cells}
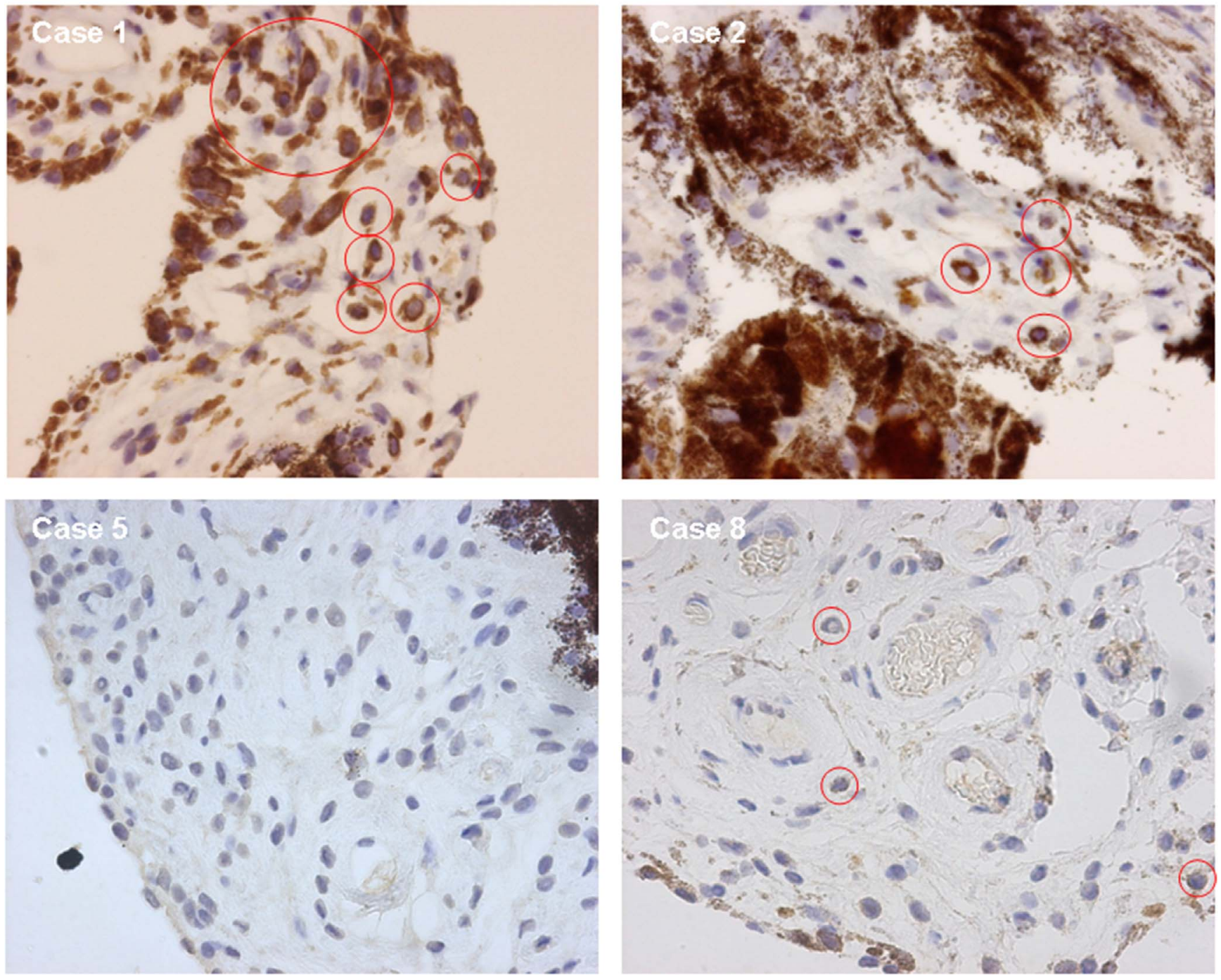

Figure 2. CD4 immunohistochemical analysis of iridectomy specimens obtained during elective trabeculectomy in four patients with uveitis associated with JIA (cases 1, 2, 5, and 8). Positive cells are marked with circles. Magnification: $10 \times 40$.

1:1600; Novocastra via Leica Biosystems, Nussloch, Germany), and mouse anti-CD138 (MCA 68-1H, 1:500; Serotec, Kidlington, UK) to identify the presence of plasma cells. A horseradish peroxidase (HRP) technique was used in an automated immunostainer. Appropriate antibody isotype control has been performed using tonsil tissue for anti-CD4, CD8, CD 20, and CD 68 , and bone marrow for anti-CD 138. Immunohistochemical sections were examined under a light microscope at $\times 400$ magnification.

\section{Results}

\section{Histopathologic Findings}

Table 1 shows the summary of the demographics, and clinical and histopathologic characteristics of the patients, and the respective iris tissue specimens. All but 2 samples were obtained while the patients were still receiving systemic immunosuppressive therapy, whereby methotrexate was the most commonly used agent (regardless of the standard pretreatment regimen with systemic corticosteroids 2 days before surgery, Table 1). All but two specimens (cases 6 and 18) were obtained during the first surgery on these eyes.

\section{Histopathologic Findings in Uveitis Cases}

A low grade inflammatory infiltrate was present in $8 / 12(67 \%)$ specimens with JIA-associated uveitis. Clinically mild uveitis activity before surgery (no more than a trace of cells in the aqueous humor) was observed in 1/12 (8\%) of the JIA-uveitis cases (case 5), in 1 non-JIA ANA-positive (case 13), 2 non-JIA ANA-negative (cases 17 and 19) anterior uveitis, and in one case with idiopathic panuveitis (case 25, Table 1). Figure 1 shows the typical histopathologic findings observed in selected JIA and non-JIA specimens. The lymphocyte infiltration was most pronounced in case 2 (JIA; Fig. 1A), 17 (anterior uveitis; Fig. 1B), and 23 (intermediate uveitis, Table 1). All uveitis cases with an inflammatory infiltrate, except one, showed a nongranulomatous type of inflammation. The exception, case 3 (ANA-negative JIA) showed a pronounced granulomatous inflammation characterized by an abundance of macrophages with giant cells and collagen destruction (Fig. 1B). In this case, 


\section{ANA+ JIA CD8+ T cells}
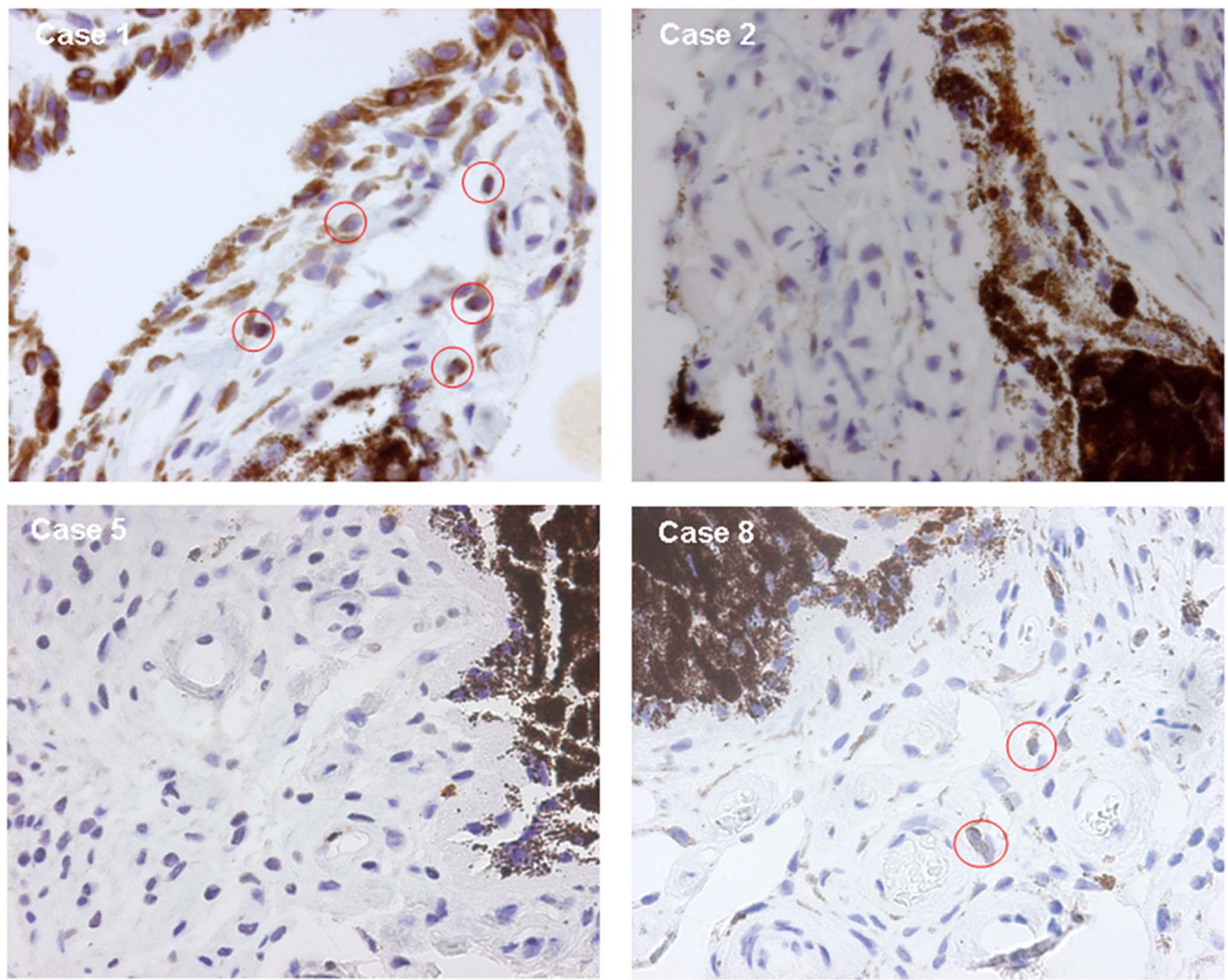

FIGURE 3. CD8 immunohistochemical analysis of iridectomy specimens obtained during elective trabeculectomy in four patients with uveitis associated JIA (cases 1, 2, 5, and 8). Positive cells are marked with circles. Magnification: $10 \times 40$.

no additional material was available for further immunohistochemical staining.

Fibrosis was present in 3 uveitis specimens (cases 3, 10, and 17; Table 1). No obvious differences could be detected by histology between eyes with mild uveitis activity compared to inactive eyes. No inflammatory infiltrate was detected in two iris tissue specimens obtained from cases with a mild clinical uveitis activity (cases 15 and 19).

\section{Histopathologic Findings in Noninflammatory Control Cases}

A mild lymphocyte infiltration was found in 2 paired iris specimens of a patient with congenital glaucoma (cases 26 and 27). Of six nonuveitic glaucoma iris specimens, three showed fibrosis. None of the control iris samples showed the presence of plasma cells or macrophages.

A low grading score for lymphocytes and signs of fibrosis was shown to overlap between uveitis cases of different origin and even with some control specimens with congenital glaucoma (Table 1)

\section{Immunohistochemical Findings}

Results of the additional immunostaining of the iris of all specimens with an inflammatory infiltrate and whereby sufficient material was available are presented in Table 2. CD138+ plasma cells could be detected in all specimens of patients with ANA-positive anterior uveitis, regardless whether they had been diagnosed with JIA or not (Table 2). Four ANApositive oligoarticular JIA cases showed a variable and mixed inflammatory infiltrate in the iris. CD138+ plasma cells and CD68+ macrophages always were present in the inflammatory infiltrate in these cases with a general predominance of plasma cells. CD4+ and CD8+ T cells were variably present in the JIA specimens, with perhaps a slight predominance of CD4+ cells (Figs. 2-6). Three cases also showed a variable number of $\mathrm{CD} 20+$ cells (Table 2). No relation between the presence of synechia of the iris and the histologic/immunohistochemical findings could be detected. A patient with mildly active JIA uveitis (case 5) showed predominantly CD 138+ plasma cells and a minimal presence of macrophages in combination with the absence of $\mathrm{T}$ cells and CD 20+ B cells. 


\section{$\mathrm{ANA}+\mathrm{JIA}$ CD20+ B cells}
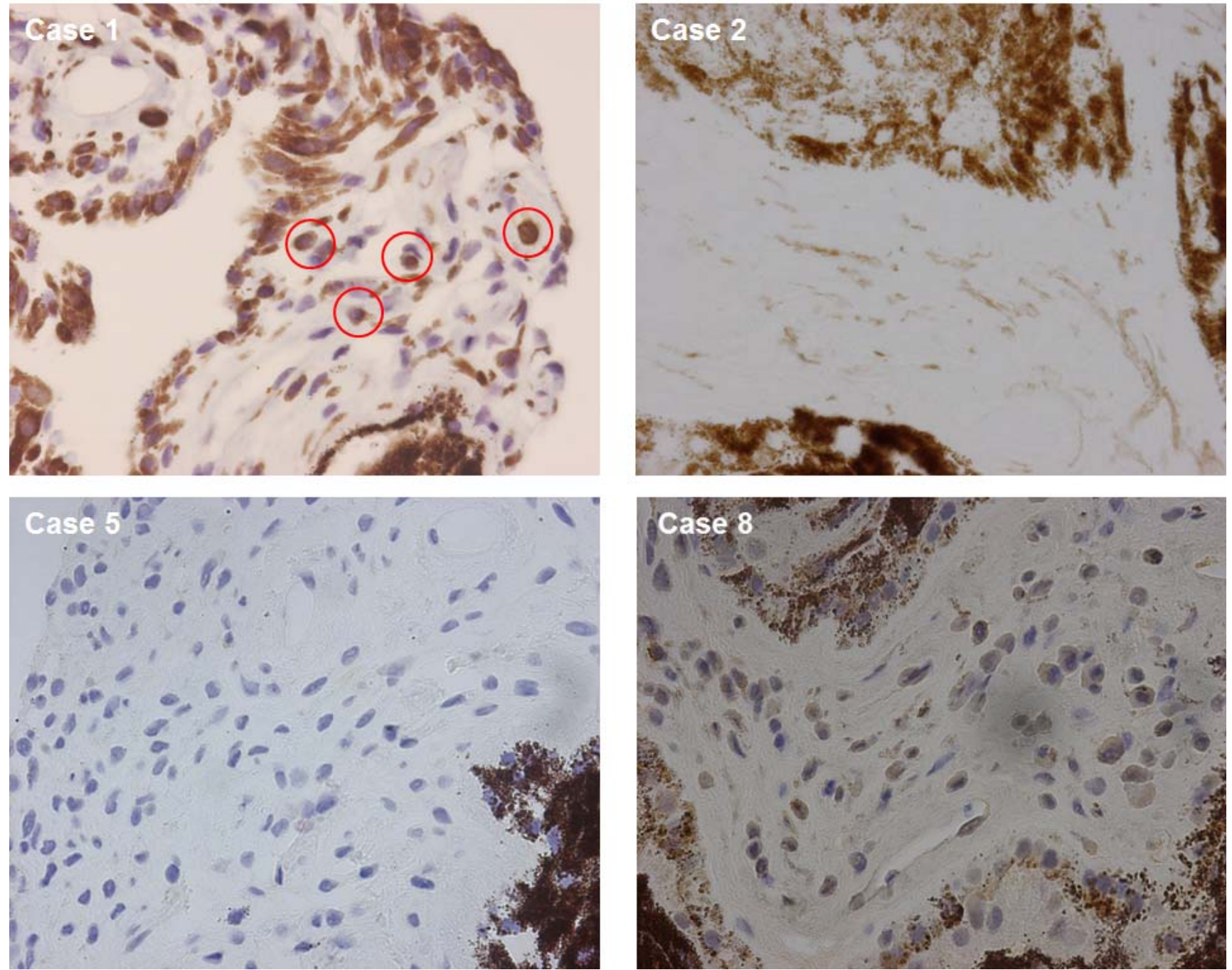

Figure 4. CD20 immunohistochemical analysis of four iridectomy specimens obtained during elective trabeculectomy in four patients with uveitis associated with JIA (cases 1, 2, 5, and 8). Positive cells are marked with circles. Magnification: $10 \times 40$. Case 8 shows a slight background staining of plasma cells which is not a true CD20 staining.

\section{Discussion}

To our knowledge, this is the first histologic and immunohistochemical study of iridectomy specimens from patients with JIA-associated uveitis, whereby a comparison is made with observations in other pediatric uveitis entities and noninflammatory controls. It is noteworthy that despite a quiescent clinical state of uveitis in the majority of the cases, some of them still had a significant infiltration of inflammatory cells in the iris.

Plasma cells, the final differentiation stage of B cells, were relatively abundant in the JIA specimens. These findings are consistent with earlier histologic studies on enucleated eyes and one iridectomy sample in JIA-uveitis, which report plasma cells to be the most prominent cell type infiltrating the iris, suggesting an important role for B cells in the pathogenesis of JIA-uveitis. $^{2-5}$ Table 3 summarizes the findings of previous studies on this subject. Summarizing the literature and our findings, it seems that in early and end-stage inflammation, plasma cells are the most prominent cell type in the iris inflammatory infiltrate. Earlier studies suggested active local immunoglobulin production by these cells (Table 3 ), although the target antigen of these antibodies was not identified. ${ }^{2-4}$ Parvovirus B19 recently has been suggested as a possible target as evidenced by the detection of locally produced intraocular antibodies against this virus in $54 \%$ of patients with JIA, compared to $7 \%$ of children with anterior uveitis of unknown origin. ${ }^{10}$ However, the antibody findings could not be confirmed by detecting parvovirus B19 DNA. This might either suggest a low grade infection, or a B lymphocyte associated immunologic phenomenon in which the virus has triggered an autoimmune response before being cleared from the eye. ${ }^{10}$ In our study, the presence of plasma cells in the cellular inflammatory infiltrate in uveitis was observed only in ANApositive patients, which is comparable with findings in the synovial fluid of JIA patients. ${ }^{11}$ However, earlier studies from our group showed that local production of intraocular antibodies against parvovirus B19 was found in ANA-positive and ANA-negative children. ${ }^{10}$ Unfortunately, no iris material for immunohistochemical staining for plasma cells was available 


\section{ANA+ JIA CD68+ Histiocytes}
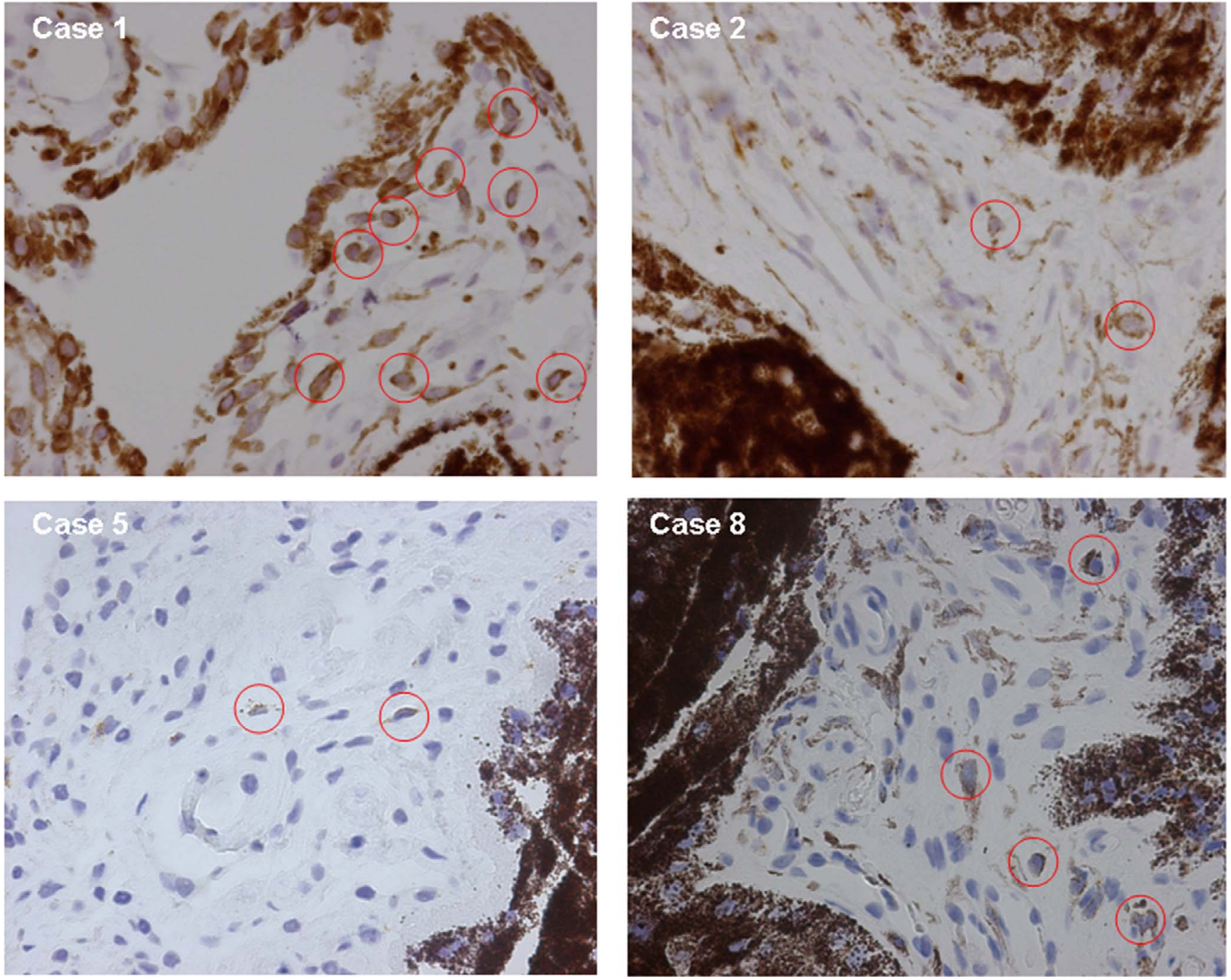

FiguRE 5. CD68 immunohistochemical analysis of iridectomy specimens obtained during elective trabeculectomy in four patients with uveitis associated with JIA (cases 1, 2, 5, and 8). Positive cells are marked with circles. Magnification: $10 \times 40$.

from our ANA-negative JIA patients and further collection of iris tissues from this subgroup of patients is necessary to address this issue in the future.

Besides the presence of plasma cells, variable numbers of CD68+ cells also could be observed in all the JIA specimens. $\mathrm{CD} 68+$ macrophages are a hallmark of an activated innate immune system, but also have an important role in the adaptive immune system. It now is assumed that both systems are involved in the pathogenesis of noninfectious uveitis and JIA. ${ }^{12,13}$

Despite the predominance of plasma cells in the inflammatory infiltrate in our JIA cases, only one of them showed the presence of $\mathrm{B}$ cells (CD20+). Besides the younger age of this patient, no other obvious differences in patient characteristics were detected compared to the three other JIA cases. It has been suggested previously that pathogenic mechanisms in JIA may vary, depending on the age of onset of JIA. Patients with recent disease and early onset ( $<6$ years) of JIA were shown to have an increased expression of B cell related genes, compared to patients with later onset. ${ }^{14}$ It should be noted, however, that younger children display an increased activity of B cells. ${ }^{15}$ The possible involvement of $\mathrm{B}$ cells in JIA pathogenesis might have clinical implications since positive results were obtained with rituximab treatment of JIA associated uveitis that was refractory to methotrexate and TNF- $\alpha$ inhibitors. ${ }^{16}$

An important role for B cells also has been suggested for other ocular inflammatory conditions, such as necrotizing scleritis. ${ }^{17}$ This was evidenced by the observation that CD20+ cells seem to be the primary infiltrating cell type with CD68+ cells being abundant as well. Whether these B cells differentiated into plasma cells is not clear, since no plasma cell staining was performed in this study. ${ }^{17}$

To our knowledge, only one report describes an immunohistochemical analysis of ocular tissue in JIA-uveitis. Parikh et al. ${ }^{4}$ described the findings in an enucleated eye after 7 years of disease (Table 3). While our main findings regarding infiltration of plasma cells are in agreement with this study, there is a discrepancy concerning the presence of CD4+ cells. In the study of Parikh et al., ${ }^{4}$ CD4+ cells were seen only occasionally in the ciliary body and pars plana, but not in the iris. Although our immunohistochemical data in JIA only included four cases, we found CD4+ T cells to be more prominently present in the iris biopsies than CD8+ T cells, which is opposite to the results obtained in the Parikh study. This could be due to the fact that 
ANA+ JIA CD138+ Plasma cells
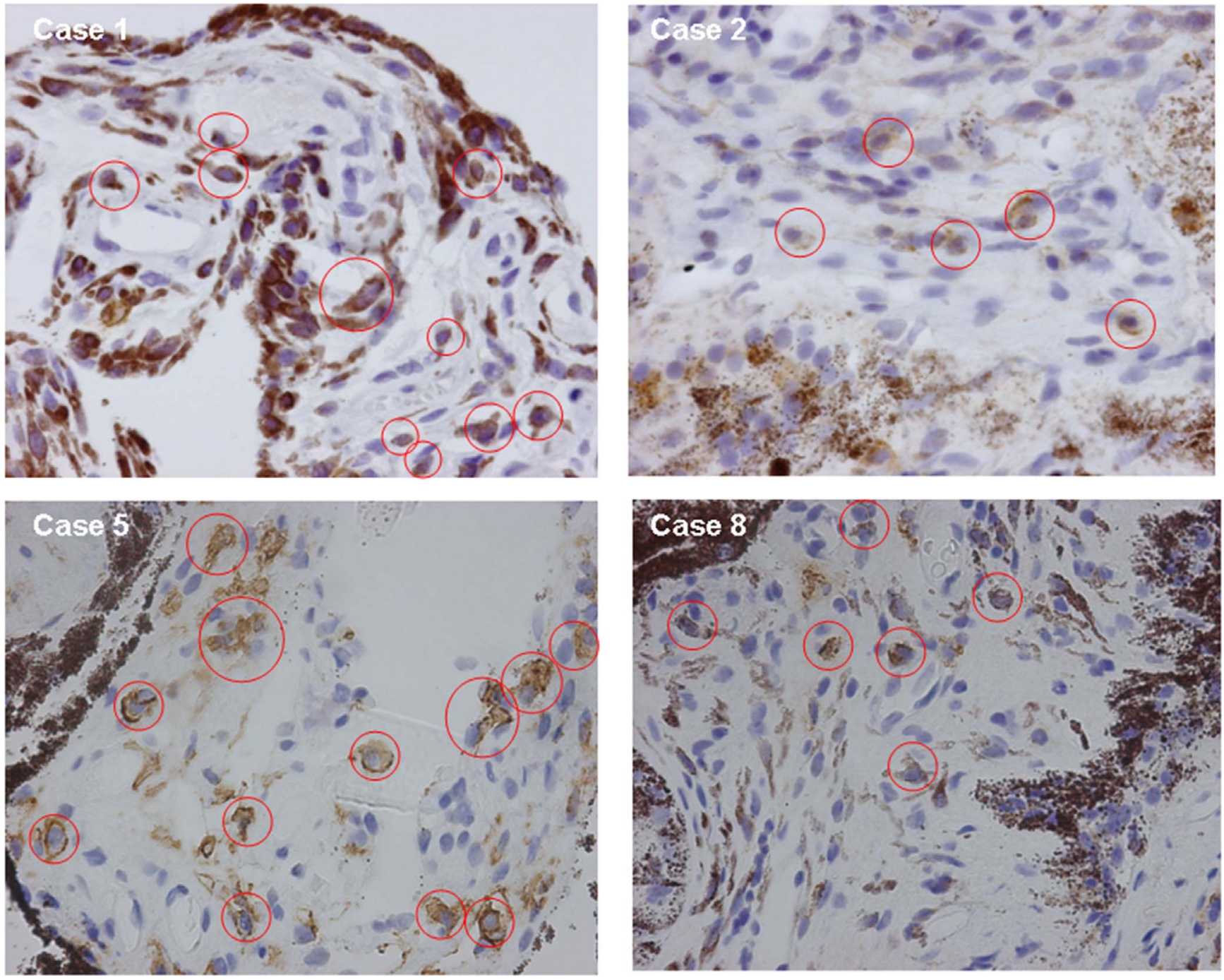

FigURE 6. CD138 immunohistochemical analysis of iridectomy specimens obtained during elective trabeculectomy in four patients with uveitis associated with JIA (cases 1, 2, 5, and 8). Positive cells are marked with circles. Magnification: $10 \times 40$.

they described an end-stage histologic picture in an enucleated eye, while our results represent eyes in an earlier course of the disease. Differences in treatment, including the use of antiTNF- $\alpha$ agents in the Parikh et al. ${ }^{4}$ study might explain the low numbers of CD4+ cells in their case.
The histopathologic features in one of our JIA patients with a clinically apparent nongranulomatous ANA-negative uveitis were characterized by the presence of giant cells showing a typical picture of a nonnecrotizing granulomatous inflammation. This is a remarkable finding as uveitis in JIA

Table 3. Overview of Previously Published Histologic Reports on Ocular Specimens From Patients With Uveitis Associated With JIA

\begin{tabular}{|c|c|c|c|c|c|c|c|c|}
\hline Year & Authors & Specimen & ANA & $\begin{array}{c}\text { Age of } \\
\text { Diagnosis of } \\
\text { Uveitis, } y\end{array}$ & $\begin{array}{l}\text { Duration of } \\
\text { Uveitis }\end{array}$ & $\begin{array}{l}\text { Histologic Type } \\
\text { of Inflammation }\end{array}$ & $\begin{array}{l}\text { Predominant } \\
\text { Inflammatory } \\
\text { Cells in the Iris }\end{array}$ & Antibody \\
\hline \multirow[t]{2}{*}{1979} & Sabates et al. ${ }^{5}$ & Enucleation & NR & 3.5 & $16 \mathrm{y}$ & Nongranulomatous & Plasma cells $\dagger$ & NR \\
\hline & & Enucleation & NR & 9.5 & $7 y$ & Granulomatous (?)* & Lymphocytes, plasma cells, giant cells $\dagger$ & NR \\
\hline 1981 & Godfrey et al. ${ }^{2}$ & Iridectomy & + & 4 & $7 \mathrm{mo}$ & Nongranulomatous & Plasma cells $\dagger$ & IgM \\
\hline 1983 & Merriam et al. ${ }^{3}$ & Enucleation & + & 3 & $7 y$ & Nongranulomatous & Plasma cells, lymphocytes $\dagger$ & $\operatorname{IgG}>\operatorname{IgM}$ \\
\hline 2008 & Parikh et al. ${ }^{4}$ & Enucleation & + & 4 & $7 y$ & Nongranulomatous & $\begin{array}{l}\text { Plasma cells, CD20+ B lymphocytes, } \\
\text { T cells mostly CD8+‡ }\end{array}$ & $\begin{array}{c}\mathrm{IgG}>\mathrm{IgM} \\
\text { and IgA }\end{array}$ \\
\hline
\end{tabular}

NR, not reported.

* Several giant cells were seen; however, in the study of Parikh et al., ${ }^{4}$ where a similar histopathologic picture was seen, immunohistochemical analysis revealed that the cells mimicking giant cells were ciliary epithelial cells.

$\dagger$ Histopathologic examination.

‡ Histopathologic examination and immunohistochemical staining. 
generally is considered to be a nongranulomatous entity. ${ }^{2-4}$ However, there were no clinical reasons to doubt the diagnosis of JIA in this child in favor of, for instance, sarcoidosis, since the presentation of uveitis was typical for an association with JIA and not with sarcoidosis. Sabates et al. ${ }^{5}$ also described the presence of epithelioid cells and giant cells in the iris of a patient with a clinically nongranulomatous JIA-uveitis. However, in the absence of immunohistochemical analysis, ciliary epithelial cells might be misinterpreted as epithelioid or giant cells in these specimens. ${ }^{4}$ Although the morphologic appearance of cells infiltrating the iris in cases with a possible granulomatous nature may have looked as typical histiocytic giant cells and not like epithelial cells, we are aware of this potential misinterpretation and regret that no additional material of this iris was available for immunohistochemical analysis in our study. It is noteworthy that another study suggested that a clinically observed granulomatous uveitis might be found more often $(28 \%)$ in children with JIA than previously thought. ${ }^{18}$

Although our study provides new insights in the histopathologic picture of JIA-associated uveitis and childhood uveitis in general, we are aware of its shortcomings. Because of the surgical origin of the specimens, most of the patients had a clinically quiet chronic uveitis and showed an absent to mild inflammatory infiltrate in the iris. This was the cause for the fact that we only had a small number of specimens that were suitable for detailed immunohistochemical analysis. Analysis of brown immunohistochemical staining (HRP technique) in pigmented iris was not problematic for an experienced pathologist in combination with the morphology following of HE staining. Due to the low number and heterogeneity of these specimens no quantitative analysis was possible. The small size of the iris tissue biopsies limited the amount of tissue sections that could be generated and restricted us in the number of markers that we could use for immunohistochemical analysis. We also are aware that the immunosuppressive treatment of our patients may have confounded our results. Despite these limitations we believe that this is a unique study as well as the largest series on this specific topic in the literature until now. Inclusion of pediatric control tissues without uveitis is another strong point of this study. Although the used control specimens are not ideal from a scientific point of view, this was the best possible ethical solution.

In summary, our study showed a predominance of plasma cells in inflammatory infiltrates in iris tissue samples obtained from children with ANA-positive uveitis regardless of whether they carry the diagnosis of JIA. Further studies concerning these iris plasma cells are necessary and should include steps to identify the as yet unknown target antigens. Such studies may help to unravel the complex pathogenesis of JIAassociated uveitis and noninfectious idiopathic anterior uveitis in children

\section{Acknowledgments}

The authors thank Aize Kijlstra for his review and the editorial correction of the manuscript.

Supported in part by the Dr F. P. Fischerstichting, ODAS-stichting, and SNOO, The Netherlands. The authors alone are responsible for the content and writing of the paper.

Disclosure: V. Kalinina Ayuso, None; M.R. van Dijk, None; J.H. de Boer, None

\section{References}

1. de Boer J, Wulffraat N, Rothova A. Visual loss in uveitis of childhood. Br J Ophthalmol. 2003;87:879-884.

2. Godfrey WA, Lindsley CB, Cuppage FE. Localization of IgM in plasma cells in the iris of a patient with iridocyclitis and juvenile rheumatoid arthritis. Arthritis Rheum. 1981;24:11951198.

3. Merriam JC, Chylack LT Jr, Albert DM. Early-onset pauciarticular juvenile rheumatoid arthritis. A histopathologic study. Arch Ophthalmol. 1983;101:1085-1092.

4. Parikh JG, Tawansy KA, Rao NA. Immunohistochemical study of chronic nongranulomatous anterior uveitis in juvenile idiopathic arthritis. Ophthalmology. 2008;115:1833-1836.

5. Sabates R, Smith T, Apple D. Ocular histopathology in juvenile rheumatoid arthritis. Ann Ophthalmol. 1979;11:733-737.

6. Caspi RR. A look at autoimmunity and inflammation in the eye. J Clin Invest. 2010;120:3073-3083.

7. Berntson L, Fasth A, Andersson-Gare B, et al. Construct validity of ILAR and EULAR criteria in juvenile idiopathic arthritis: a population based incidence study from the Nordic countries. International League of Associations for Rheumatology. European League Against Rheumatism. J Rheumatol. 2001;28: 2737-2743.

8. Krumrey-Langkammerer M, Hafner R. Evaluation of the ILAR criteria for juvenile idiopathic arthritis. J Rbeumatol. 2001;28: 2544-2547.

9. Jabs DA, Nussenblatt RB, Rosenbaum JT. Standardization of uveitis nomenclature for reporting clinical data. Results of the First International Workshop. Am J Opbthalmol. 2005;140: 509-516.

10. de Groot-Mijnes J, Dekkers J, de Visser L, Rothova A, van Loon A, de Boer JH. Antibody production against B19 virus in ocular fluid of JIA-associated uveitis patients. Ophthalmology. 2015; 122:1270-1272.

11. Gregorio A, Gambini C, Gerloni V, et al. Lymphoid neogenesis in juvenile idiopathic arthritiscorrelates with ANA positivity and plasma cell infiltration. Rheumatology (Oxford). 2007;46: 308-313.

12. Prakken B, Albani S, Martini A. Juvenile idiopathic arthritis. Lancet. 2011;377:2138-2149.

13. Willermain F, Rosenbaum JT, Bodaghi B, et al. Interplay between innate and adaptive immunity in the development of noninfectious uveitis. Prog Retin Eye Res. 2012;31:182-194.

14. Barnes MG, Grom AA, Thompson SD, et al. Biologic similarities based on age at onset in oligoarticular and polyarticular subtypes of juvenile idiopathic arthritis. Arthritis Rheum. 2010;62:3249-3258.

15. Shearer WT, Rosenblatt HM, Gelman RS, et al. Lymphocyte subsets in healthy children from birth through 18 years of age: the Pediatric AIDS Clinical Trials Group P1009 study. J Allergy Clin Immunol. 2003;112:973-980.

16. Heiligenhaus A, Miserocchi E, Heinz C, et al. Treatment of severe uveitis associated with juvenile idiopathic arthritis with anti-CD20 monoclonal antibody (rituximab). Rheumatology (Oxford). 2011;50:1390-1394.

17. Usui $\mathrm{Y}$, Parikh J, Goto $\mathrm{H}$, et al. Immunopathology of necrotising scleritis. Br J Ophthalmol. 2008;92:417-419.

18. Keenan JD, Tessler HH, Goldstein DA. Granulomatous inflammation in juvenile idiopathic arthritis-associated uveitis. J AAPOS. 2008;12:546-550. 